\title{
ПРОБЛЕМА ОБОСНОВАНИЯ В РАБОТАХ АРМЯНСКИХ И РОССИЙСКИХ ФИЛОСОФОВ
}

Понятие «обоснование» традиционно используется широко, будь то научная, или художественная литература, или же устная речь. Универсальность обоснования в прагматическом плане следует объяснять его функциональной широтой: обосновать можно все и вся. Не вдаваясь в особенности таких логикометодологических процедур, как, например, доказательство, можно вместо этого просто сказать: «Я обосновал свою мысль», и, как правило, такое выражение будет понято адекватно. Вместе с тем, обратное не столь приемлемо: вместо обоснования понятие доказательство в непрофессиональной (т.е. не связанной с логико-философской экспликацией данных понятий) речи не используется, ибо это повлечет за собой требование представить конкретные факты в подтверждение высказанной и «доказанной» мысли, что может оказаться затруднительным. Даже обыденный опыт свидетельствует о том, что обоснование более гибко и емко, чем иные, схожие и связанные с ним понятия.

Аналогичными примерами изобилует не только обыденный язык и даже не столько художественная, сколько - научная литература, где исследование определенной проблемы, выбор соответствующей методологии исследования, определение объекта и предмета исследования, изложение выводов представляются как обоснование.

Такой подход можно считать целесообразным, несмотря на кажущуюся содержательную разбросанность значения понятия обоснование. Среди разнообразных примеров приведения обоснования в заголовках и текстах на- учных статей и книг можно проследить определенную закономерность, связывающую все эти примеры в единое целое, а именно: обоснование используется в значении объяснения сделанного выбора в пользу того или иного подхода к проблеме. Это - интересная закономерность, определяющая то, как и почему автор той или иной концепции пришел к тому или иному варианту решения поставленной проблемы. Это, по нашему мнению, является наиболее широким в функциональном плане содержанием понятия обоснование.

Так, например, автор политологической статьи под названием «Модели обоснования морали» К.Н.Калмыков, как и большинство не связанных с исследованием самой проблемы обоснования авторов, не вдается в анализ содержания понятия обоснование, а использует его в традиционном, неопределенно-общедоступном смысле, благодаря чему читатель обращает внимание не на обоснование, а на то, что подвергается этому обоснованию, а именно (в данном случае) на «Модели морали». К.Н.Калмыков пишет: «Обсуждение проблем морали, включая ее отношение с политикой в современном мире, предполагает обращение к истории обоснования моральных норм... В настоящей статье предпринята попытка рассмотреть поиск новых основ легитимности морали в интеллектуальных проектах мыслителей Модерна. В качестве базового материала для анализа были выбраны труды Ларошфуко, Локка, Руссо и де Сада» (Калмыков 2002: 117).

Можно заметить, что К.Н.Калмыков использует обоснование в значении выбора и 
указания на один из возможных подходов к проблеме определения морали, на тот или иной вариант построения модели морали у того или иного автора. Обоснование здесь контекстуально может трактоваться как ответ на вопрос, «почему и как» тот или иной мыслитель определил свой подход к проблеме морали.

Обоснование можно определить как демонстрацию, описание и объяснение правильности, целесообразности специфического подхода автора к выбору проблемы и путям ее решения.

Аналогичное, контекстуальное (за отсутствием в большинстве работ с использованием понятия обоснование прямого его определения) определение понятия обоснование возникает при прочтении иных научных работ, посвященных «обоснованию» конкретной научно-практической задачи. Так, во взятой из области экономических исследований статье Скробиных «Обоснование структур и функций системы управления маркетингом в сельскохозяйственных предприятиях Ярославской области» (Скробин, Скробин 2001) «обоснование» лишь указывается в качестве одного из ключевых терминов, однако, подобно многим научным работам с «обоснованием» в заглавии и тексте, здесь содержание понятия «обоснование» не раскрывается, а сама статья посвящена сугубо маркетинговым исследованиям. Однако, это не является чем-то странным, т.к., как было отмечено, огромное количество заголовков научных трудов с использованием «обоснования» относится к узконаучным, специфическим исследованиям, никак не относящимся к исследованию и даже к попытке определить обоснование. Тем не менее, в данной статье так же, как и в большинстве других, можно обнаружить общую логику использования понятия обоснование как авторский подход к конкретной проблеме и выбору стратегии ее решения. В частности, в данной статье авторы пытаются объяснить свой интерес к проблемам маркетинговых исследований, предлагая применение маркетинговых технологий для решения сельскохозяйственных проблем, указывая на ценность подобного подхода и его эффективность. Это и есть обоснование в указанном нами широком значении.

Интересно заметить, что данное широкое определение обоснования очень близко к одному из наиболее распространенных определений обоснования, которое дается авторами статьи «Обоснование» в Философской энциклопедии (1967): «Возможно и более широкое понимание Обоснования - как регламентации, эталонизации продуктов любой познавательной деятельности, включая и выработку «идеального плана» практического действия. Объектом такого Обоснования в принципе может выступать любой конкретный продукт умственного труда, выработка которого предваряет его непосредственное использование. Следовательно, Обоснование выступает здесь не как оценка в системе знания, пусть и развивающегося, а как оценка в системе деятельности. С этой т.зр. Обоснование... научная гипотеза, выдвигаемая как средство предвидения ранее не наблюдавшихся фактов, или практическое решение о выборе места строительства предприятия, т.к. в обоих случаях предлагаются некоторые средства для будущего действия и важно знать, насколько уже имеющийся социальный опыт обеспечивает их соответствие (конечно, всегда приблизительное) целям их применения (Асмус, Денисова, Иовчук и др. 1967: 111).

Итак, обоснование может быть использовано и широко используется в обыденной и профессиональной лексике, указывая на определенный подход к выбору предмета дискурса, к определению некой проблемы, к выбору методов и способов ее решения. Это касается также выбора той или иной теоретической концепции в качестве основы научного исследования, обоснование означает также выбор 
исходных принципов, на которых строится теория, и т.д.

Однако, анализ области нефилософского (нелогического) применения обоснования, выявление и сопоставление примеров употребления термина «обоснование» неспециалистами в области философии и логики обоснования (т.е. теми, кто активно использует термин «обоснование» в собственном профессиональном и обыденном дискурсах, не исследуя и не вдаваясь в подробности самой проблемы обоснования), все же далеко не достаточен для определения и специфизации собственного содержания обоснования. На более глубинном уровне анализа непосредственно сталкиваемся с вопросом специфики обоснования в ряду взаимосвязанных категорий философского анализа дискурса, а именно - аргументации, доказательства, убеждения, определения, оправдания.

Действительно, основная трудность определения и исследования специфики обоснования заключается в логико-методологической и даже традиционно-прагматической взаимосвязанности процедуры обоснования с аргументацией, доказательством, определением, мотивацией и другими взаимосвязанными категориями. Прежде всего, указанные категории исследованы непропорционально. Так, проблема доказательства кажется более исследованной, во всяком случая, является более частым предметом логико-методологических и междисциплинарных исследований (например, в математике, логике, криминологии, психологии), чем, скажем, аргументация, которая стала интереснейшим объектом логикометодологических исследований совсем недавно (см: Hovhannisyan 2001: 34-37), а междисциплинарные исследования аргументативных процессов (в политологии, психологии, правоведении и др. областях) вообще толькотолько появляются (Атанесян 2002). Ряд других взаимосвязанных понятий, таких, как убежде- ние, мотивация и т.д., разработаны в основном в современной психологии и, как правило, такие разработки страдают отсутствием логико-методологической, аргументативной стороны процессов убеждения, что не менее существенно для понимания этих явлений.

Основатель Ереванской школы аргументации академик Г.А.Брутян указывает на содержательно-функциональную взаимосвязь и логически-родственную природу процесса обоснования и таких мыслительных феноменов, как доказательство, аргументация, убеждение, объяснение (см., например: Брутян 1984, 1992).

Действительно, эти процессы обладают рядом сходств, например, структурных: во всех этих процедурах выдвигается некий тезис, приводятся доводы (аргументы) в его поддержку. Поэтому, исследуя проблему обоснования, неслучайно рассмотрение таких понятий, как поддержка, защита тезиса. Эти понятия в связи с проблемой определения понятия обоснование рассматриваются А.Амирханян, которая исследует работы Э.Блейра, Ф.Еемерена и Р.Грутендорста, Е.Барта и Э.Краббе, пытаясь найти взаимосвязь между понятием обоснование и понятиями поддержка, защита, используемыми этими авторами. Как видно из данного исследования, указанные понятия характерны как для обоснования, так и для других мыслительных процедур, прежде всего для аргументации (Амирханян 1998: 40-52).

Тем не менее, сходства между указанными процедурами не следует рассматривать как их тождественность. Как было отмечено выше, функ циональная схожесть этих понятих не означает их взаимозаменяемости, в частности, по причине различных объемов этих понятий. Кроме того, возможность использования одного понятия вместо другого (например, использование понятия аргументация вместо доказательства правомерно лишь в случае указания на структуру процесса, где приводятся аргу- 
менты. Опять же, речь идет о контексте, в котором одно понятие может выступать в значении другого, или же, наоборот, выступать в своей специфике.

Такая взаимосвязь этих понятий, безусловно, усложняет выявление особенностей, специфики обоснования. Вместе с тем, с помощью экстраполяции качеств более исследованных процессов (например, аргументации) на менее исследованные (на обоснование) становится возможным само исследование обоснования, что следует рассматривать как положительный фактор. Таким образом, проблему обоснования невозможно исследовать вне системы взаимосвязанных понятий аргументации, доказательства, убеждения и т.д., а также прагматического и ситуационного контекста их использования. Тем не менее, в преобладающем большинстве немногочисленных специальных работ встречаем именно одностороннее отождествление обоснования с аргументацией, убеждением, доказательством.

Так, теоретик в области проблемы обоснования Е.П.Никитин указывает на зависимую от контекста синонимичность терминов «обоснование» и «доказательство», «эмпирическая проверка», «нравственное оправдание», «объяснение», «вывод» и т.п., из чего делает вывод о допустимости исследования всех вышеуказанных понятий под общим названием «обоснование»: «То широкое значение, которое мы пытаемся придать ему (понятию «обоснование» - А.А.) в этой работе и которое, следовательно, согласуется с нашей интуицией, для кого-то из читателей может оказаться неприемлемым» (Никитин 1981: 21). И действительно, трудно согласиться с подобным широким толкованием данной категории, при котором «размываются» собственное содержание и специфические особенности процесса обоснования.
Аналогичное широкое толкование термина «обоснование» встречаем у Я.С.Яскевич, которая, по-существу, отождествляет понятия «обоснование» и «аргументация» (см.: Яскевич 1998: 45, 476).

Данная тенденция характерна также для работ А.А.Ивина по проблемам аргументации и риторики (см., например: Ивин 2000, 2002). А.А.Ивин отождествляет аргументацию и обоснование, вероятно, исходя из общности структур данных процедур, где из определенных оснований в соответствии с логическими законами выводится следствие. В его работах понятия аргументация и обоснование постоянно чередуются, взаимозаменяются, так что создается ощущение их полной тождественности. Более того, к обоснованию А.А.Ивин сводит также и другие логико-методологические процедуры, например, доказательство. Определение одного из этих понятий через другое очень характерно для работ А.А.Ивина, что не позволяет получить однозначное, специфическое содержание данных понятий (концепция А.А.Ивина будет подробно рассмотрена далее).

Сложность однозначного определения понятия обоснование связана так же с наличием ряда взаимосвязанных с данным понятием терминов, которые в научной, художественной, публицистической и др. литературе нередко взаимозаменяются, несмотря на то, что по содержанию не совпадают и сами нуждаются в конкретизации и однозначном определении так же, как и само понятие обоснование. Среди подобных терминов следует назвать обоснованность, основания, основы. Данные термины создают естественную логико-языковую возможность для конкретизации понятия обоснование, для определения его специфики по отношению к таким понятиям, как аргументация, доказательство, определение, убеждение и др. Однако, на деле некоторые авторы используют их в универсальном плане с целью 
подстроить все подобные логические конструкции под единую логическую модель, представив их или как доказательство, или как риторику, и т.п. Так, автор статьи в Логическом словаре-справочнике Н.И.Кондаков обращает особое внимание на понятие обоснованность, связывая данный термин не с обоснованием, а с доказательством, скорее, с доказанностью (мы объясняем это тем, что понятие доказательство более определенно и лучше разработано, чем обоснование). Н.И.Кондаков пишет: «Обоснованность - такое качество правильного логического мышления, которое свидетельствует о том, что в рассуждении все мысли опираются на другие мысли, истинность которых доказана. Необоснованность мыслей (суждений), из которых строится то или иное умозаключение, ведет к ложным выводам» (Кондаков 1975: 396).

Можно заметить, что Н.И.Кондаков связывает обоснованность с истинностью, правильностью, логичностью мышления. Между тем, данные качества нисколько не показывают специфики обоснования, отличительных особенностей данной мыслительной процедуры по сравнению, скажем, с доказательством. У Н.И.Кондакова «Доказательство (в широком, содержательном плане) - логическое действие, в процессе которого истинность какой-либо мысли обосновывается с помощью других мыслей...» (Кондаков 1975: 158). Как видим, обоснованность Н.И.Кондаков определяет через доказанность, а доказательство - через обоснованность. Кроме того, что более ценно, обоснование у Н.И.Кондакова вырисовывается в качестве метода доказательства: доказываем с помощью обоснования.

Размытость в определении данных логических процедур встречаем также, например, в Толковом словаре русского языка (хотя лингвистическое определение логических процедур может служить лишь одним из способов определения логических понятий, но не единственным). Здесь встречаем определения содержаний слов «обоснованный» и «обосновать» («Обоснование» в словаре Волина и Ушакова вообще не указывается): «Обоснованный - мотивированный, основательный, подтвержденный серьезными доводами» (Волин, Ушаков 1938: 691). Там же читаем: «Обосновать - подкрепить доказательствами что-нибудь; привести убедительные доводы для доказательства чего-нибудь, доказать правильность чего-нибудь» (Волин, Ушаков 1938: 691). Как видим, здесь деятельность по обоснованию, представленная терминами «обоснованный» и «обосновать», связывается с такими качествами, как, например, мотивированность (ассоциируется с наличием определенных мотивов - субъективных оснований, об истинности которых, например, в юриспруденции можно говорить только в случае их объективной подтвержденности, соответствии реальным фактам). Тем не менее, это не мешает авторам определить термин «Обосновать» с помощью терминов «доказать», «подкрепить доказательствами», что однозначно предполагает истинность следствий из истинных оснований. Налицо противоречивость в определении терминов «Обоснованность» и «Обосновать»: в первом случае предполагается субъективность и возможность неистинных оснований, во-втором - истинность оснований и доказательHOCTb.

Безусловно, обоснование выделяется из ряда взаимосвязанных процедур аргументации, доказательства, убеждения и др. по ряду признаков, к анализу которых лишь подходят некоторые авторы. Одной из попыток исследования проблемы и специфики обоснования предпринял автор данной статье в исследовании Гегелевской концепции обоснования (Атанесян 2000). Указанные академиком Г.А.Брутяном принципиальные особенности обоснования в системе аргументации наводят на ряд идей, отражающих, на наш взгляд, воз- 
можности специального изучения обоснования в системе аргументативных процессов, т.е. тем самым определяется то общее поле (область аргументативных процессов), в котором следует искать место и специфическую роль обоснования. В частности, этому могут способствовать те определения обоснования, в которых понятие обоснование определяется через аргументацию.

В одной из своих работ Г.Г.Шакарян выделяет обоснование как аргументативную деятельность и вместе с тем как ценностно-познавательную рефлексию, в которой объективное содержание знания наделяется прагматическим, а также этико-аксиологическим значением и значимостью (см.: Шакарян 1996).

Г.А.Брутян предлагает методологическое разграничение процедур обоснования, доказательства, аргументации, рассматривая феномен обоснования в системе теории аргументации. Автор, в частности, пишет: «Под «обоснованием» в теории аргументации мы будем иметь в виду процесс оценки защищаемого тезиса аргументации, как и опровергаемого антитезиса, средств доказывания и опровержения (в том числе аргументов и контраргументов), установления целесообразности выбора из истинных утверждений именно тезиса аргументации, оправдания цели аргументации и т.д.» (Брутян 1984: 31). Автор пишет: «Можно утверждать, что если доказательство - способ установления истины и, следовательно, истина - его цель, то в обосновании преобладает оценочный момент.

С учетом этого обстоятельства и можно эксплицировать понятие обоснование для нужд теории аргументации следующим образом. Обоснование в процессе аргументации это способы оценки средств и форм аргументативного дискурса, защищаемого тезиса и опровергаемого антитезиса, что дает возможность установить целесообразность выбора те- зиса среди равноистинных высказываний» (Брутян 1992: 103).

Определения обоснования, данные Г.А.Брутяном, являются исходными для ряда ученых, пытавшихся приблизиться к выделению специфик обоснования в связи с другими видами аргументативных процедур. С этой точки зрения наиболее интересным представляется сравнительный анализ понятий аргументация, доказательство, обоснование, предпринятый В.И.Свинцовым. Прежде всего, В.И.Свинцов пытается установить различия между обоснованием и доказательством: «Под доказательством (доказыванием) понимают процедуру установления истинности некоторого высказывания путем его выведения из других высказываний. С этой точки зрения к обоснованию целесообразно было бы относить операции, подтверждающие некоторое положение, сообщающие последнему большую или меньшую степень вероятности. Иными словами, различие между доказательством и обоснованием допустимо усматривать в оценке получаемого посредством соответствующих процедур знания как в одном случае достоверного, в другом - вероятного» (Свинцов 1986: 166).

Как видим, в качестве критерия различения процедур обоснования и доказательства В.И.Свинцов предлагает применить «степень вероятности» - получаемое в результате процедуры обоснования знание менее вероятно, чем - в результате доказательства. Более того, доказанное знание всегда максимально вероятно, т.е. достоверно, когда как обоснованное суждение менее вероятно: «Действительно, при всей их близости обоснование все же не исключает известных градаций, что как раз характерно для вероятности (можно говорить о более или менее обоснованном высказывании), тогда как относительно доказательства это было бы неверно (более или менее доказанным высказывание быть не может, 
оно либо доказано, либо еще нет)» (Свинцов 1986: 166-167).

Тем самым В.И.Свинцов подчеркивает непосредственную связь между доказательством и обоснованием, которые, по мнению ученого, являются единым процессом познания, где результат вывода показывает, доказан ли тезис, или обоснован. Получается, что доказательство и обоснование возможно различить лишь в конце познавательного процесса, т.е. обоснованность и доказанность являются качествами знания, а не процесса познания. Сам же процесс познания, будучи в той или иной степени вероятностным, является процессом обоснования, которое превращается в доказательство при стопроцентной вероятности.

В.И.Свинцов определяет обоснование следующим образом: «Итак, обоснованием целесообразно считать такую процедуру, посредством которой некоторому высказыванию (выполняющему функцию, аналогичную функции тезиса в доказательстве) сообщается определенная степень вероятности. Отличие обоснования от доказательства состоит в использовании (в функции аргументов) вероятных высказываний и (или) вероятных (нестрогих) выводов операций» (Свинцов 1986: 167). Причем, нетрудно усмотреть единство процессов обоснования и доказательства в гносеологическом плане, где качество знания по степени вероятности видна лишь на заключительном этапе познания: «Если значение вероятности определять в интервале от 0 до 1, то достижение крайнего «правого» ее показателя равносильно превращению вероятного знания в достоверное. Это показывает близость и соответствующих аргументационных процедур: доказательство в принципе можно толковать как вполне совершенную форму обоснования (обоснование же - как незавершенное, редуцированное, неполное, усеченное доказательство» (Свинцов 1986: 168).
Как видим, у В.И.Свинцова обоснование и доказательство представляют собой единый процесс познания, где качество полученного знания, определяемое степенью достоверности/вероятности, становится результатом или доказательства (достоверное, окончательное знание), или - обоснования (вероятное знание).

В.И.Свинцов пишет: «Сопоставляя доказательство и обоснование с аргументацией, нельзя не заметить, что в первых двух из названных процедур коммуникативные аспекты факультативны; они могут либо отступать на второй план, либо даже вообще отсутствовать. Это имеет место тогда, когда доказательство (обоснование) ${ }^{1}$ выполняет сугубо познавательную функцию. ...Доказательство (обоснование) здесь оценивается только со стороны формальной правильности, т.е. исключительно в логико-методологическом аспекте. Обнародование доказательства (научная публикация с его воспроизведением, защита диссертации и т.п.) переносит процедуру доказывания в область интеллектуально-речевого обмена и тем самым делает ее содержанием аргументации. В этом случае аргументация сливается с доказательством или, точнее, сводится к последнему. Но это отношение тождества между доказательством и аргументацией имеет место далеко не всегда» (Свинцов 1986: 169).

Как видим, понятие аргументация у В.И.Свинцова несколько шире обоснования и доказательства и включает также коммуникационные, риторические компоненты, иными словами, процедуры убеждения.

Можно сказать, что определение обоснования, данное В.И.Свинцовым, является очень важным для понимания одной из особенностей процедуры обоснования - его вероятност-

\footnotetext{
1 Как видим, в качестве процесса познания В.И.Свинцов отождествляет процедуры доказательства и обоснования, считая качествами единого познавательного процесса.
} 
ного характера, причем ученый пишет о вероятностном характере выводов в результате обоснования не как о чем-то неполноценном и отрицательном (такую тенденцию можно заметить у Гегеля), а как о необходимой компоненте познания, как о процессе, приводящем в конечном счете к достоверному, полному знанию.

Тем не менее, как нам кажется, В.И.Свинцов обратил недостаточное внимание именно на коммуникационно-риторическую и ценностную компоненты процедуры обоснования, на которые указал мельком. Более того, ученый видит более тесную связь между обоснованием и доказательство, чем - обоснованием и аргументацией, когда как мы считаем обоснование более характерным аргументативным процессом, наделенным бо'льшим набором аргументативных техник и приемов, чем доказательство, которое по сути является аргументативной процедурой благодаря структуре, а не разнообразию риторических компонент.

По нашему мнению, вероятностный характер выводов как принцип определения обоснования и достоверность выводов в доказательстве, данные В.И.Свинцовым, на самом деле являются не единственным, а лишь одним из критериев определения обоснования в системе аргументативных процессов.

Итак, одним из наших определений обоснования, предлагаемых в этой работе, является обоснование как оценка и выбор. На наш взгляд, обоснование как аргументативная процедура, в отличие от доказательства, предоставляет свободу выбора, и именно этим является более притягательной и более удобной логической конструкцией, чем доказательство, в котором требования истинности посылок, истинности заключения и правильности, непротиворечивости, однозначности вывода предполагают ограниченность, нередко - отсутствие возможности выбора, отсутствие свободы действия, что является затруднительным и нежелательным из чисто человеческих соображений. Человек стремится к свободе - к свободе мысли и действия, по сути - к возможности выбора. Пожалуй, именно возможность и свобода выбора являются условиями счастья, которое всегда так трудно определить. Обоснование зиждется именно на возможности выбора среди идей, мыслей, желаний, действий. Обосновать можно как теоретическую концепцию, так и практическое решение (об этом см., например: Атанесян 2002, Атанесян 2003: 4164, Атанесян 2004: 129-140).

С этой точки зрения нам кажется верным определение обоснования, данное в Философском энциклопедическом словаре (1983): «Обоснование, мыслительная процедура, основанная на использовании определенных знаний, норм и установок для принятия какихлибо утверждений, оценок или решений о практических действиях. Социально-значимая деятельность человека обусловлена определенными нормами, предпосылками и установками, выступающими в качестве ее регулятивов. Их применение в процедуре обоснования предполагает обсуждение и анализ правомерности и целесообразности их использования в некоторой ситуации, сопоставление возможных альтернатив и выбор из них наиболее эффективной» (Ильичев, Федосеев, Ковалев, Панов 1983: 446).

Обоснование характерно как для теоретической, так и для практической деятельности. В научной деятельности построение той или иной концепции является результатом обоснования (обоснование научной теории, концепции). Обоснование научной концепции - это прежде всего выбор определенного направления исследования, оценка проблемной ситуации, оценка по ряду специфических обще- и внутринаучных критериев теоретических основ исследования, выбор и обоснование научной методики и техники исследования, и т.д. 
Именно такое понимание обоснования в научной литературе имплицитно распространено и соответствует нашему определению.

Обоснование в практической деятельности является ее неотъемлемой частью. Проблема оценки и выбора, т.е. обоснования, является извечной, воспетой Шекспиром и многими другими мыслителями, задававшимися вопро-

\section{ЦИТИРОВАННАЯ $И$} УПОМЯНУТАЯ ЛИТЕРАТУРА

1. Амирханян, А. (1998). Экспликация понятия обоснование. Ереван: Изд-во НАН РА "Гитутюн".

2. Асмус, В., Денисова, Л.Ф., Иовчук, М.Т. (ред., 1967). «Обоснование». В: Философская энциклопедия, т. 4, сс. 110-111.

3. Атанесян, А.В. (2000). Гегелевская концепция обоснования. Ереван: Изд-во НАН РА «Гитутюн».

4. Атанесян, А. (2002). Обоснование в принятии политических решений. Ереван: Изд-во НАН РА «Гитутюн».

5. Атанесян, А.В. (2003). «Обоснование в принятии политических решений: подходы к проблеме». В: Человек-СообществоУправление (Журнал Кубанского госуниверситета), 4, (сс. 41-64).

6. Атанесян, А. (2004). «Стратегия «перетягивания» и перераспределение сил на постсоветском пространстве». В: Мир Перемен (Международный научно-общественный журнал Института международных экономических и политических исследований Российской академии наук), 2, (сc. 129-140).

7. Брутян, Г.А. (1984). Аргументация. Ереван: Изд-во АН АрмССР.

8. Брутян, Г.А. (1992). Очерк теории аргументации. Ереван: Изд-во АН Армении.

9. Волин, Б.М., Ушаков, Д.Н. (ред., 1938). Толковый словарь русского языка, Т. 2. сом правильности человеческого решения. Человек выбирает постоянно, всю жизнь, руководствуясь различными доводами - своими и чужими, прибегая к самоаргументации или обращаясь к аргументам других людей, основывая свои действия на знании и/или практическом опыте.

Москва: Гос. Издательство иностранных и национальных словарей.

10. Ивин, А.А. (2000). Теория аргументации. M.

11. Ивин, А.А. (2002). Риторика: искусство убеждать. М.: Фаир-Пресс.

12. Ильичев, Л.Ф., Федосеев, П.Н., Ковалев, С.М., Панов, В.Г. (ред., 1983). Философский энциклопедический словарь, статья «Обоснование». М.: «Советская энциклопедия», (с. 446).

13. Калмыков, К.Н. (2002). «Модели обоснования морали: Интеллектуальные проекты Ларошфуко, Локка, Руссо, де Сада». В: пОЛИС, N 5, (с. 117).

14. Кондаков, Н.И. (1975). Логический словарь-справочник. Москва: «Наука».

15. Никитин, Е.П. (1981). Природа обоснования. Москва: «Наука».

16. Свинцов, В.И. (1986). «К вопросу о соотношении понятий «аргументация», «доказательство», «обоснование». В: Брутян, Г.А., Нарский, И.С. и др. (ред.). Философские проблемы аргументации. Ереван: Изд-во АН АрмССР, (сс. 165-172).

17. Скробин Ю.Б., Скробин И.Ю. (2001). «Обоснование структур и функций системы управления маркетингом в сельскохозяйственных предприятиях Ярославской области». В: Маркетинг в России и за рубежом, N 1.

18. Шакарян, Г.Г. (1996). «Этико-ценностный взгляд на аргументацию» (на арм. яз.). В: 
Вестник Ереванского университета, 2, (сс. 3-15).

19. Яскевич, Я.С. (1998). «Аргументация». Новейший философский словарь, (с. 45).

20. Яскевич, Я.С. (1998). «Обоснование». Новейший философский словарь, (с. 476).
21. Hovhannisyan, H. (2001). «International Activity of the Yerevan School for Argumentation». In: Society in Transformation, N 1,2, (pp. 34-37).

ATAHECЯH АРTУP

\section{ПРОБЛЕМА ОБОСНОВАНИЯ В РАБОТАХ АРМЯНСКИХ И РОССИЙСКИХ ФИЛОСОФОВ}

PEЗЮME

\begin{abstract}
Исследования вопросов аргументации являются одним из перспективных направлений в ряде областей современной науки - в философии, политологии, психологии, риторике, лингвистике, и т.д. Аргументативный дискурс представляет собой интереснейший междисциплинарный объект исследований, привносящий гуманистическую природу и ценностное измерение в любую сферу жизнедеятельности человека и общества. Обоснование как разновидность аргументации (Г.А. Брутян, Ереванская школа аргументации) является на сегодняшний день наименее разработанным понятием в исследованиях аргументативного дис-
\end{abstract}

курса, определяя собой особенности аргументации в ряде вопросов, таких как аргументирование необходимости принятия того или иного политического решения, указывание на целесообразность, необходимость того или иного действия, на правильность выбора из альтернатив. Данная статья посвящена анализу современных концепций и взглядов на проблему обоснования в трудах армянских и российских ученых.

Ключевые понятия: обоснование, аргументация, дискурс, доказательство, убеждение, Ереванская школа аргументации.

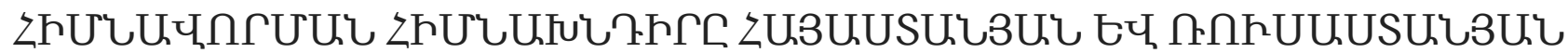

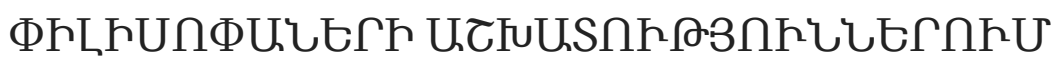

\section{UUФกФПЋU}

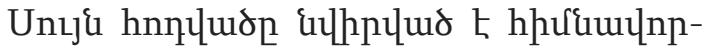

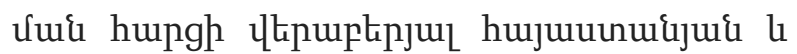

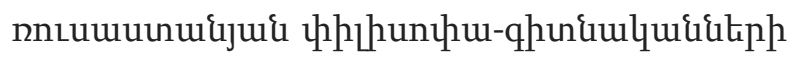

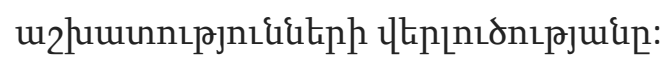

Фuuunupluरuif hungtiph nLuntưuuup-

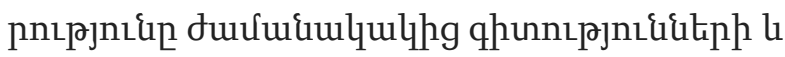

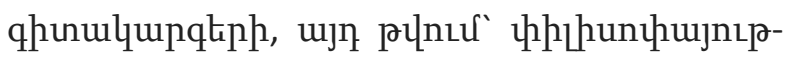
jui, punupuqhunnıрjui, hnqtpuinıpjui, 


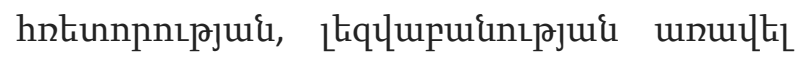

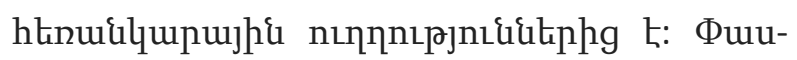

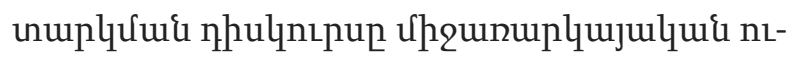

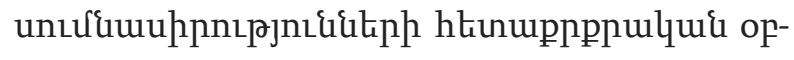

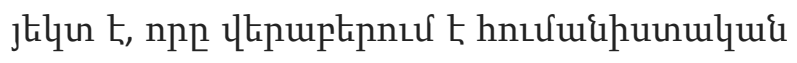

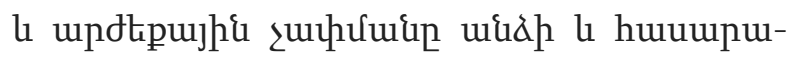

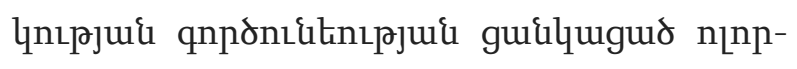

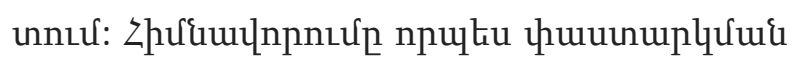

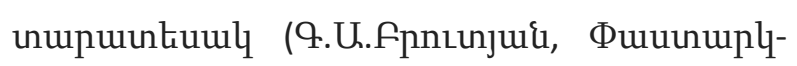

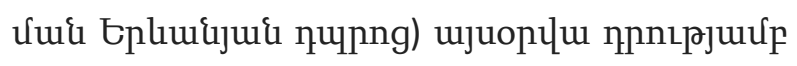

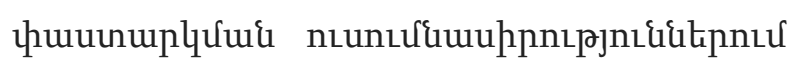

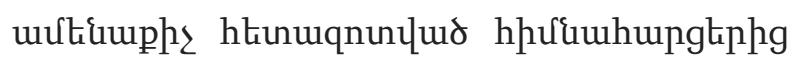

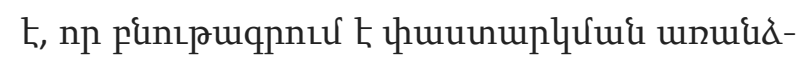

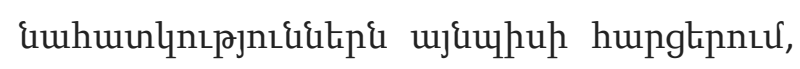
hisuhuhp tis punupulqui uju que uje

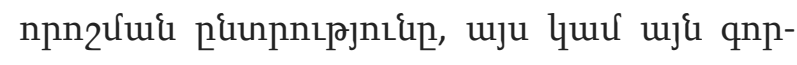

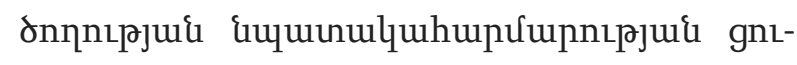

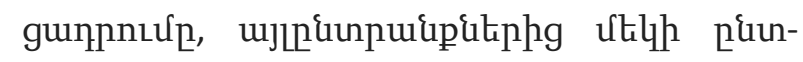

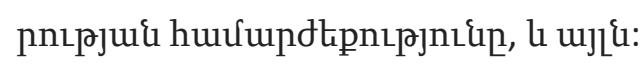

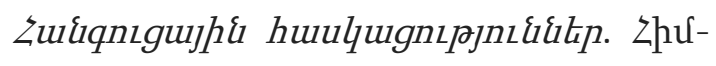

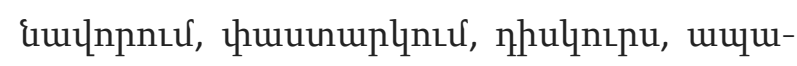

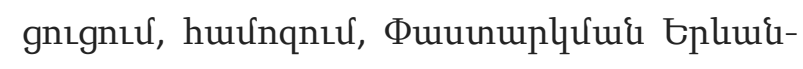
juif nu्png:

ATANESYAN ARTHUR

\section{THE PROBLEM OF JUSTIFICATION IN THE WORKS OF ARMENIAN AND RUSSIAN PHILOSOPHERS}

\section{SUMMARY}

Argumentation studies are nowadays one of the perspective research directions in the number of sciences, including philosophy, political sciences, psychology, rhetoric, linguistics, etc. Argumentative discourse is an interdisciplinary research object, which brings with itself very humanistic and value measurement to any field of human and social activities. Justification as type of argumentation (G. A. Brutian, Yerevan School of Argumentation), is among those less studied terms in the argumentative discourse research, which determines by itself peculiarities of argu- mentation in the range of issues, such as justification of the necessity to make a certain political decision, demonstration of the need and rationality to take a certain action, focusing on one of the proposed alternatives to choose. The article is devoted to comparative and contemporary studies of justification in the works of Armenian and Russian scholars.

Key concepts: justification, argumentation, discourse, proof, persuasion, Yerevan School of Argumentation. 